\title{
Stability of Imipenem and Cilastatin Sodium in Total Parenteral Nutrient Solution
}

\author{
Dayid S. Zaccardelli, Pharm.D., Claudia Sanders Krcmarik, B.S, Robert Wolk, Pharm.D., and \\ Nabil Khalidi, Pharm.D.
}

From the Department of Pharmacy Services, and College of Pharmacy, University of Michigan, Ann Arbor, Michigan

\begin{abstract}
The chemical stability and compatibility of imipenem-cilastatin sodium (Primaxin) in two different total parenteral nutrient (TPN) solutions was determined. TPN solutions consisted of $4.25 \%$ and $5 \%$ amino acids with $25 \%$ and $35 \%$ dextrose, respectively.

Imipenem-cilastatin sodium was constituted with $10 \mathrm{ml}$ of sterile water and admixed with $90 \mathrm{ml}$ of TPN solution for a final concentration of $5 \mathrm{mg} / \mathrm{ml}$ of each drug. The final solutions were assayed at times 0 (immediately after admixture), $15 \mathrm{~min}$, $30 \mathrm{~min}, 1,4,8$, and $24 \mathrm{hr}$ by a stability-indicating highperformance liquid chromatographic assay. Concurrently, test TPN solutions were monitored for $\mathrm{pH}$ changes, color changes, and precipitate formation. The potential effect of imipenemcilastatin sodium on the stability of amino acids and other
\end{abstract}

TPN additives was not evaluated.

Imipenem and cilastatin sodium was stable $(\geq 90 \%$ recovered) in each TPN solution at $15 \mathrm{~min}$. A significant $(\geq 10 \%)$ and steady decrease of imipenem recovery occurred at subsequent sampling times. Cilastatin appeared more stable than imipenem in both TPN solutions. A physical color change from colorless to dark orange appeared in each TPN solution over the 24-hr study period.

Imipenem-cilastatin sodium is stable for $15 \mathrm{~min}$ in the TPN solutions studied; however, until the stability of the amino acids can be determined, the antibiotic should be administered through a separate line or Y-site while the TPN infusion is interrupted. (Journal of Parenteral and Enteral Nutrition 14:306-309, 1990)
Imipenem-cilastatin sodium (Primaxin) is a broad spectrum intravenous antimicrobial product. Imipenem is a beta-lactam antibiotic of a $\mathrm{N}$-formimidoyl derivative of thienamycin. Cilastatin sodium is a competitive inhibitor of a renal hydrolysis enzyme, dehydropeptidase $\mathrm{I}^{1}$ Cilastatin sodium, having no intrinsic antimicrobial activity, retards the renal metabolism of imipenem. ${ }^{2}$ Imipenem is effective against aerobic and anaerobic Grampositive, Gram-negative, and beta-lactamase producing organisms. ${ }^{3-6}$

Imipenem-cilastatin sodium, being a broad spectrum antibiotic, is commonly used in the multiinfected septic patient. The septic patient is occasionally a candidate for total parenteral nutrient (TPN) solution due to the acute stress of sepsis. Complications of sepsis include gastrointestinal ileus, increased caloric requirements and decreased consciousness which result in inadequate oral nutritional intake. Therefore, TPN solution administration may be required for nutritional support. TPN solution administration has been shown to be effective for nutritional support in inpatient and outpatient settings. ${ }^{\top 9}$

In the critical care patient it would be useful to infuse imipenem-cilastatin sodium into TPN solution at a Ysite for various reasons:

1. These patients may have limited access sites for drug administration especially when other intravenous fluids are being administered concomitantly.

2. Y-site administration would reduce the number of direct intravenous lines into the patient, resulting in decreased line and site maintenance by nursing staff.

Received for publication. May 23, 1989.

Accepted for publication. August 21, 1989.
Since imipenem-cilastatin sodium is a new antimicrobial agent, the stability and compatibility have not been determined in TPN solution. Merck, Sharp and Dohme, the manufacturer of Primaxin, states that imipenemcilastatin remains potent for $4 \mathrm{hr}$ at room temperature in various intravenous solutions. ${ }^{10}$ Recently, Bigley et $\mathrm{al}^{11}$ examined the stability and compatibility of imipenem-cilastatin sodium (Primaxin) in seventeen intravenous solutions. ${ }^{11}$ Results indicate that Primaxin is most stable in $0.9 \%$ sodium chloride and sterile water for injection. Stability and compatibility of imipenem-cilastatin sodium with TPN formulations have not been established. Therefore, the objective of this study was to determine the chemical stability and compatibility of imipenem-cilastatin sodium in two different TPN solutions by high-performance liquid chromatography (HPLC).

\section{METHODS}

\section{Experimental Design}

Two aseptically prepared TPN solutions were used to evaluate imipenem-cilastatin sodium stability and compatibility (Table I). All procedures were carried out under continuous fluorescent room lighting at room temperature $\left(25^{\circ} \mathrm{C}\right)$.

Primaxin $500 \mathrm{mg}$ (Merck, Sharp and Dohme, West Point, PA, Lot $0422 \mathrm{~N}$ ) (500 mg of imipenem anhydrous/ $500 \mathrm{mg}$ cilastatin) was aseptically constituted with $10 \mathrm{ml}$ of sterile water and then admixed with $90 \mathrm{ml}$ of TPN solution in $150 \mathrm{ml}$ evacuated infusion bottles, resulting in a $5-\mathrm{mg} / \mathrm{ml}$ mixture of imipenem and cilastatin. The procedure was repeated in duplicate for TPN solutions 1 and 2. 
Each test TPN mixture was aseptically sampled at time 0 (immediately after admixture), $15 \mathrm{~min}, 30 \mathrm{~min}, 1$, 4, 8, and 24 hr. Each sample was assayed in duplicate using HPLC.

\section{Assay Procedure}

Imipenem and cilastatin concentrations were measured by HPLC in a manner similar to that described by Bigley et al. ${ }^{11}$ Chemical analysis by HPLC was performed because it is sensitive and specific for molecular stability. HPLC determination is superior to visual and microbiological studies since there is a lack of correlation between these techniques and chemical stability. ${ }^{12}$ The stability of amino acids or other TPN additives following addition of the imipenem-cilastatin sodium was not evaluated.

Samples were diluted 1:100 with the aqueous mobile phase $(0.004 \mathrm{M}$ 3-[N-morpholino]propanesulfonic acid (MOPS) buffer with sodium hexane sulfate $2 \mathrm{~g} /$ liter plus $4 \mathrm{ml}$ of acetonitrile and $5 \mathrm{ml}$ of methanol added to each liter). The mobile phase was adjusted to $\mathrm{pH} 7.00$ with sodium hydroxide. Thirty microliters from each diluted

TABLE I

Composition of TPN solutions

\begin{tabular}{lcc}
\hline \multirow{2}{*}{ Component } & \multicolumn{2}{c}{ Amount per liter of TPN } \\
& \multicolumn{2}{c}{ solution } \\
\cline { 2 - 3 } & Solution 1 & Solution 2 \\
\hline Amino Acids (g)* & 42.5 & 50 \\
Dextrose (g) & 250 & 350 \\
Calcium (mEq) & 4.5 & 4.5 \\
Magnesium (mEq) & 5.0 & 5.0 \\
Potassium (mEq) & 40.0 & 40.0 \\
Sodium (mEq) & 35.0 & 35.0 \\
Acetate (mEq) & 74.5 & 74.5 \\
Chloride (mEq) & 52.5 & 52.5 \\
Phosphorus (mM) & 12.0 & 12.0 \\
Heparin (units) & 1000 & 1000 \\
\hline
\end{tabular}

* Aminosyn, Abbott Laboratories, North Chicago, IL, lot 02-503DM-03. sample was injected through a Rheodyne injector 125 valve (Rheodyne injector 125 valve. Rheodyne Inc. Cotati. CA) $1100-\mu \mathrm{L}$ loop 1 onto a Hewlett-Packard RP-8 $(20 \mathrm{~cm} \times 0.46 \mathrm{~cm}$ internal diameter) column (Hewlet Packard, Abondale. PAl. A Waters model 6000A solvent delivery system (Waters Associates. Milturd. PA) and a Lamda Max 481 LV detector (Lamda Max 481 LV detector, Waters Associates) were used. Peak areas were measured automatically by a Hewlett-Packard model $3390 \mathrm{~A}$ integrator. HPLC assay specifications were as follows: absorbance wavelength $250 \mathrm{~nm}$. A LFS 0.1, response time $0.1 \mathrm{sec}$, attenuation 4 , chart speed $0.8 \mathrm{~cm} /$ min, and flow rate $1.8 \mathrm{ml} / \mathrm{min}$. The retention time was 5.5 and $8.8 \mathrm{~min}$ for imipenem and cilastatin. renpectively. All solvents and water were HPLC grade.

\section{Stability-Indicating Procedures}

The HPLC assay used to determine imipenem and cilastatin concentrations was stability indicating.: A standard of $1.0 \mathrm{mg} / \mathrm{ml}$ (drugs/water) was prepared for imipenem-cilastatin sodium. This standard was divided into three portions and stressed in one of three ways: the $\mathrm{pH}$ of the standard was adjusted to 1.8 with phosphoric acid, the standard solution was evaporated on a hot plate and allowed to dry at excessive heat before reconstitution to the exact initial volume with water, or the standard was heated on a boiling water bath for fifteen minutes. A standard $(100 \mu \mathrm{g} / \mathrm{ml})$ was prepared from each of the three stressed standards and analyzed by HPLC. Resulting chromatographs were compared with those from freshly prepared standards. The assay proved to be stability indicating; no drug decomposition product interfered with the response of the intact drug under the stressed conditions described above (Fig. 1).

\section{Assay Validation}

A standard solution $(1 \mathrm{mg} / \mathrm{ml})$ of Primaxin in mobile phase was prepared on three separate days. A standard

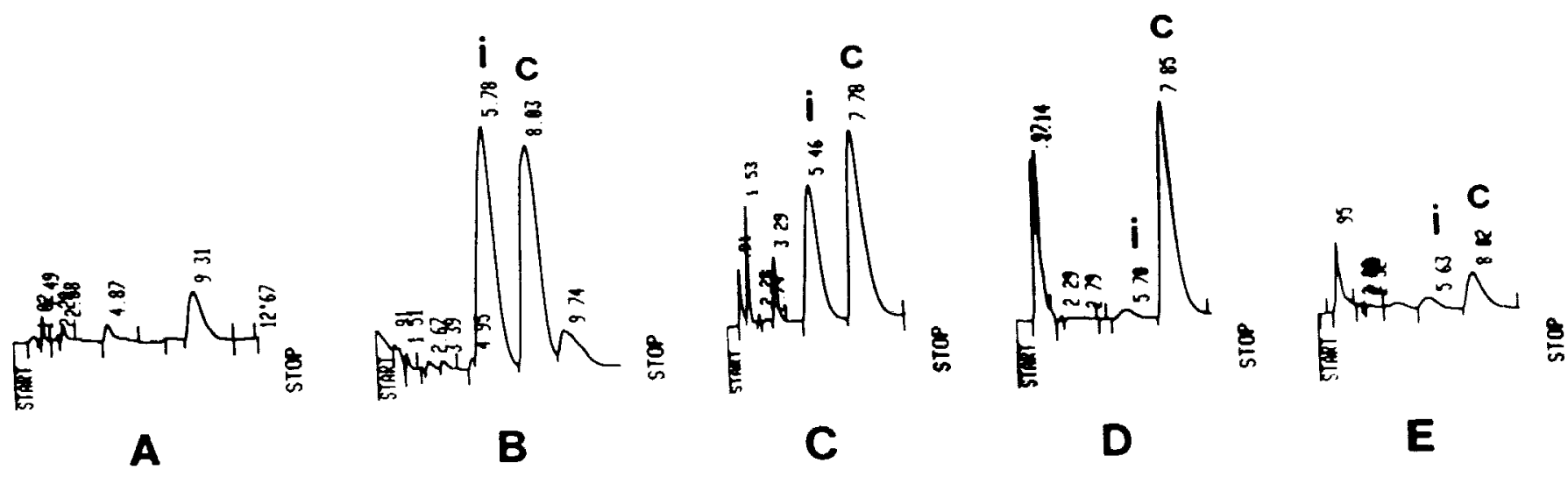

\section{Minutes}

FIG. 1. Chromatographs of TPN solution $1(1: 100)$ in mobile phase $(A)$ : Imipenem $(50 \mu \mathrm{g} / \mathrm{ml}$ ) and cilastatin $(50 \mu \mathrm{g} / \mathrm{ml})$ in TPX solution 1 at time zero $(B)$ : Imipenem $(43 \mu \mathrm{g} / \mathrm{ml})$ and cilastatin $(43 \mu \mathrm{g} / \mathrm{ml})$ after $15 \mathrm{~min}$ in a boiling water bath $(C)$, at $\mathrm{pH} 1.8(D)$. and after being heat dried and reconstituted $(E)$. In chromatographs $B . C, D$. and $E$, peaks for imipenem and cilastatin are marked $i$ and $c$, respectively. All other peaks in chromatographs $C, D$, and $E$ are degradation products. 
curve was performed in duplicate on each das over a concentration range of 0 to $86.4 \mu \mathrm{g} / \mathrm{ml}$ of imipenem and cilastatin. The slope of each curve was calculated by linear least-squares regression analysis. The six standard curves were reproducible (imipenem slope $=7.30 \pm 0.20$; cilastatin slope $=7.28 \pm 0.48$ ) and linear (imipenem $\mathrm{r}^{2}$ $=0.9991 \pm 0.0004$; cilastatin $\left.r^{2}=0.9991 \pm 0.0003\right)$. Based on the slope of each standard curve, a calculated concentration was computed for each peak area. The percent deviation for each calculated concentration was computed as follows:

\section{calculated concentration - actual concentration calculated concentration $\times 100 \%$}

The average percent deviation of the calculated concentrations for imipenem and cilastatin standard curves was $2.15 \% \pm 2.93 \%$ and $2.15 \% \pm 2.83 \%$, respectively.

\section{pH Measurement and Solution Color}

Each test TPN solution was analyzed for $\mathrm{pH}$ and physical changes at each sampling time. An electrode Corning $135 \mathrm{pH}$ meter was used. At each sampling time an additional $3-\mathrm{ml}$ aliquot was removed and analyzed for $\mathrm{pH}$ changes. Concomitantly, visual inspection for color and/or precipitate formation was recorded.

\section{Data Analysis}

Imipenem and cilastatin concentration and percent recovery for each sample were calculated. Sample concentrations were calculated from a line generated by least squares regression from the average of the six standard curves according to the following equation: $y=m x+b$. Drug recovery at time 0 was considered to be $100 \%$; all other values were determined from this point. The percent recovery mean and standard deviation (unbiased) were calculated for each sampling time. A change of potency of more than $10 \%$ was considered to be significant; less than $90 \%$ recovery was considered to indicate instability. ${ }^{11,13}$

\section{RESULTS}

Drug recovery from all samples analyzed is presented in Table II. Imipenem $(5 \mathrm{mg} / \mathrm{ml})$ was stable $(\geq 90 \%$ recovered) in TPN solutions 1 and 2 at $15 \mathrm{~min}$. Imipenem had significant $(\geq 10 \%$ ) degradation in both TPN solutions at $1 \mathrm{hr}$. In TPN solution 2, imipenem was completely degraded at $24 \mathrm{hr}$. Cilastatin was stable in TPN solutions 1 and 2 at $30 \mathrm{~min}$, and was generally more stable than imipenem over time. Color observations and pH measurements of all solutions are presented in Table III. A gradual color change from colorless to dark orange was observed over $24 \mathrm{hr}$ in both TPN solutions. There were no significant $\mathrm{pH}$ changes and no detectable precipitate during the study period.

\section{DISCUSSION}

Establishment of an intravenous product's stability with various intravenous solutions allows greater flexibility and convenience for administration. Generally, antibiotics and TPN solutions should be administered through separate intravenous lines. ${ }^{14}$ However, in certain clinical situations, it would be advantageous to mix the antibiotic with TPN solution or to administer them at a Y-site with TPN solution.

This study demonstrated that imipenem-cilastatin sodium at a concentration of $5 \mathrm{mg} / \mathrm{ml}$ was stable in TPN solutions 1 and 2 for $15 \mathrm{~min}$ (Table III). At $30 \mathrm{~min}$ imipenem-cilastatin sodium remained stable in TPN solution 2 , but not in solution 1 , and at $1 \mathrm{hr}$ it was not stable in either solution. Therefore, imipenem-cilastatin sodium stability with the TPN solutions could not be established after 15 to $30 \mathrm{~min}$. Regardless of whether stability is established at 15 or $30 \mathrm{~min}$, direct admixture of imipenem-cilastatin in a TPN bottle is not practical. However, in clinical practice actual contact time between imipenem-cilastatin sodium and TPN solution during administration via a $\mathrm{Y}$-site would be less than $30 \mathrm{~min}$.

Gradual color change in both TPN solutions seemed to be correlated with the degradation of imipenem and/ or cilastatin. Since both drug components were in solution together, the absolute relationship between degradation of imipenem or cilastatin and the evolution of color was indistinguishable. However, the color change

TABLE III

pH and color changes*

\begin{tabular}{|c|c|c|c|c|c|c|c|c|}
\hline \multirow[b]{2}{*}{ Solution ${ }^{\dagger}$} & \multirow{2}{*}{$\begin{array}{c}\text { Before } \\
\text { admixture }\end{array}$} & \multicolumn{7}{|c|}{ Sampling time } \\
\hline & & $0 \mathrm{hr}$ & $15 \mathrm{~min}$ & $30 \mathrm{~min}$ & $1 \mathrm{hr}$ & $4 \mathrm{hr}$ & $8 \mathrm{hr}$ & $\begin{array}{l}24 \\
\mathrm{hr}\end{array}$ \\
\hline \multicolumn{9}{|c|}{ Solution 1} \\
\hline $\mathrm{pH}$ & 5.52 & 5.66 & 5.66 & 5.65 & 5.64 & 5.55 & 5.47 & 5.40 \\
\hline color & 0 & 1 & 1 & 1 & 1.5 & 2 & 3 & 5 \\
\hline \multicolumn{9}{|c|}{ Solution 2} \\
\hline $\mathrm{pH}$ & 5.44 & 5.56 & 5.56 & 5.55 & 5.54 & 5.47 & 5.40 & 5.36 \\
\hline color & 0 & 1 & 1 & 1.5 & 2 & 3 & 4 & 5 \\
\hline
\end{tabular}

* Color was rated on a scale: 0 (colorless), 1 (pale yellow), 2 (yellow), 3 (dark yellow), 4 (orange), 5 (dark orange).

+ See Table I for composition of solutions 1 and 2 .

TABLE II

Stability of imipenem-cilastatin in two TPN solutions*

\begin{tabular}{|c|c|c|c|c|c|c|c|}
\hline \multirow{2}{*}{ Drug } & \multirow{2}{*}{$0 \mathrm{hr}(\mathrm{mg} / \mathrm{ml})$} & \multicolumn{6}{|c|}{$\%$ Initial concentration of drug remaining (mean $\pm \mathrm{SD}$ ) } \\
\hline & & $15 \mathrm{~min}$ & $30 \mathrm{~min}$ & $1 \mathrm{hr}$ & $4 \mathrm{hr}$ & $8 \mathrm{hr}$ & $24 \mathrm{hr}$ \\
\hline \multicolumn{8}{|c|}{ Imipenem $(5 \mathrm{mg} / \mathrm{ml})$} \\
\hline Solution 1 & $6.1 \pm 0.2$ & $95 \pm 4.0$ & $89 \pm 5.6$ & $86 \pm 3.8$ & $61 \pm 3.3$ & $43 \pm 3.5$ & $3 \pm 0.3$ \\
\hline Solution 2 & $5.8 \pm 0.1$ & $93 \pm 3.6$ & $92 \pm 2.3$ & $86 \pm 4.7$ & $59 \pm 4.1$ & $31 \pm 0.8$ & 0 \\
\hline \multicolumn{8}{|c|}{ Cilastatin $(5 \mathrm{mg} / \mathrm{ml})$} \\
\hline Solution 1 & $5.8 \pm 0.1$ & $97 \pm 6.4$ & $96 \pm 4.0$ & $88 \pm 2.6$ & $81 \pm 2.6$ & $74 \pm 4.2$ & $72 \pm 1.5$ \\
\hline Solution 2 & $4.8 \pm 0.5$ & $92 \pm 2.7$ & $95 \pm 1.1$ & $96 \pm 0.3$ & $89 \pm 3.8$ & $84 \pm 2.1$ & $66 \pm 1.8$ \\
\hline
\end{tabular}

- See Table I for composition of solutions 1 and 2 
appeared to be more closely related to the degradation of imipenem, since the color intensified as imipenem continued to degrade while cilastatin remained relatively intact. In addition, HPLC detection of degradation products appeared to be inversely proportional to decreased imipenem detection and directly proportional to color change.

\section{CONCLUSION}

Imipenem-cilastatin sodium is stable for $15 \mathrm{~min}$ in the TPN solutions studied. However, until the stability of the amino acids can be determined, imipenem-cilastatin sodium should be administered according to the manufacturer's recommendations through a separate intravenous line or if necessary, at the TPN line $\mathrm{Y}$-site while the TPN infusion is temporarily interrupted.

\section{ACKNOWLEDGMENTS}

The editorial assistance of Cary E. Johnson, Pharm.D., Associate Professor, College of Pharmacy, University of Michigan, and Debra K. Zaccardelli, Pharm.D., Clinical Pharmacist, Duke University Medical Center, in the preparation of this manuscript is acknowledged.

\section{REFERENCES}

1. Kropp H, Sundelof JG, Hajdu R, et al: Metabolism of thienamycin and related carbapenem antibiotics by renal dipeptidase dehydropeptidase-I. Antimicrob Agents Chemother 22:62-70, 1982
2. Norrby SR. Alestig $K$. Bjornegard B. et al: L'rinary recovery of $\mathcal{X}$ formimidoyl thienamycin $\left(\mathrm{MK}_{0}-5 \mathrm{-}\right)$ as affected by coadministration of $\mathrm{C}$-formimidoyl thienamycin dehydropeptidase inhibitors. Antimicrob Agents Chemother $23: 300-30 \bar{T}, 1983$

3. Merck. Sharp and Dohme: Primaxin Formulary Information Monograph. West Point. PA 1985

4. Kropp H. Sundelof JG, Kahan JS, et al: MKOT87 ( $\mathrm{N}$-formimidoy thienamycin): Evaluation of in vitro and in ivo activities. Antimicrob Agents Chemother 17:993-1000, 1980

5. Richmond RH: The semi-synthetic derivative MK078- and its properties with respect to a range of beta-lactamases from clinically relevant bacterial species. J Antimicrob Ther 7:279-285, 1981

6. Brown JE, Del Bene VE, Collins CD: In itro activity of $\mathbf{N}$ formimidoyl thienamycin. moxalactam. and other new beta-lactam agents against Bacteroides fragilis: Contribution of beta-lactamase to resistance. Antimicrob Agents Chemother 19:248-252, 1981

7. Law DH: Current concepts in nutrition: Total parenteral nutrition. N Engl J Med 297:1104-1107, 1977

8. Dudrick SJ: A clinical review of nutritional support of the patient. JPEN 3:444-451, 1979

9. Ivey $M$, Riella $M$, Miller W, et al: Long-term parenteral nutrition in the home. Am J Hosp Pharm 32:1032-1036, 1975

10. Merck, Sharp and Dohme: Primaxin package insert. West Point, PA, 1985

11. Bigley FP, Forsyth RJ, Henley MW: Compatibility of imipenemcilastatin sodium with commonly used intravenous solutions. Am J Hosp Pharm 43:2803-2809, 1986

12. Niemiec PW, Vanderveen TW: Compatibility considerations in parenteral nutrient solutions. Am J Hosp Pharm 41:893-911, 1984

13. Trissel LA: Avoiding common flaws in stability and compatibility studies of injectable drugs (editorial). Am $J$ Hosp Pharm 40:11591160,1983

14. Bertch KE: Medication mixture with parenteral nutrition solutions. Part 1. LymphoMed Nutr Newsl 5:21-26, 1985 